\title{
Three-year mortality among alcoholic patients after intensive care: a population-based cohort study
}

\author{
Steffen Christensen ${ }^{1 *}$, Martin B Johansen ${ }^{1}$, Lars Pedersen ${ }^{1}$, Reinhold Jensen², Kim M Larsen ${ }^{3}$, Anders Larsson ${ }^{4}$,
} Else Tønnesen ${ }^{3}$, Christian F Christiansen ${ }^{1}$ and Henrik T Sørensen ${ }^{1,5}$

\begin{abstract}
Introduction: Alcoholic patients comprise a large proportion of patients in intensive care units (ICUs). However, data are limited on the impact of alcoholism on mortality after intensive care.

Methods: We conducted a cohort study among 16,848 first-time ICU patients between 2001 and 2007 to examine 30-day and 3-year mortality among alcoholic patients. Alcoholic patients with and without complications of alcohol misuse (for example, alcoholic liver disease) were identified from previous hospital contacts for alcoholism-related conditions or redemption of a prescription for alcohol deterrents. Data on medication use, demographics, hospital diagnoses, and comorbidity were obtained from medical databases. We computed 30-day and 3-year mortality and mortality rate ratios (MRRs) by using Cox regression analysis, controlling for covariates.
\end{abstract}

Results: In total, 1,229 (7.3\%) ICU patients were current alcoholics. Among alcoholic patients without complications of alcoholism ( $n=785,4.7 \%$ of the cohort), 30-day mortality was $15.9 \%$ compared with $19.7 \%$ among nonalcoholic patients. Compared with nonalcoholic patients, the adjusted 30-day MRR was 1.04 (95\% confidence interval (CI), 0.87 to 1.25 ). Three-year mortality was $36.2 \%$ compared with $40.9 \%$ among nonalcoholic patients, corresponding to an adjusted 3-year MRR of 1.16 (95\% Cl, 1.03 to 1.31). For alcoholic patients with complications $(n=444,2.6 \%$ of the cohort), 30-day mortality was 33.6\%, and 3-year mortality was $64.5 \%$, corresponding to adjusted MRRs, with nonalcoholics as the comparator, of $1.64(95 \% \mathrm{Cl}, 1.38$ to 1.95$)$ and $1.67(95 \% \mathrm{Cl}, 1.48$ to 1.90$)$, respectively.

Conclusions: Alcoholic ICU patients with chronic complications of alcoholism have substantially increased 30-day and 3-year mortality. In contrast, alcoholics without complications have no increased 30-day and only slightly increased 3- year mortality.

\section{Introduction}

Alcoholism is a major public health problem [1]. An estimated 15- to 20-million people in the United States are chronic alcohol abusers, and more than 100,000 deaths in the United States are ascribed annually to alcoholism [1]. Alcoholic patients hospitalized with pneumonia or trauma or undergoing major elective surgery are at increased risk of serious complications, such as acute respiratory distress syndrome and sepsis [2-10]. The prevalence of patients in intensive care units (ICUs)

\footnotetext{
* Correspondence: sc@dce.au.dk

'Department of Clinical Epidemiology, Aarhus University Hospital, Olof

Palmes alle 43-45, Aarhus N, 8240, Denmark

Full list of author information is available at the end of the article
}

with definite alcoholism was reported to be $12 \%$ in a 1988 Danish study of 216 ICU patients [11], and as many $28 \%$ of ICU patients admitted to a UK inner-city hospital were admitted with alcohol-related complications [6].

No randomized controlled study examined the effect of alcoholism on ICU prognosis [12]. Interpretation of the few and inconsistent observational studies on the short-term prognosis of alcoholic patients in general ICUs is complicated by inclusion of highly selected study populations, such as trauma patients and patients undergoing major surgery, or by inclusion of ICU patients from hospitals primarily treating mentally ill and alcohol/drug abusing patients $[3,13,14]$. Relatively

\section{Biomed Central}


small study populations and lack of control for potential confounding factors, including comorbidity, further complicate the interpretation of the studies [2,3,6,11,13-15]. Moreover, limited data exist on whether any increased mortality is related to alcoholism itself or to chronic complications of excessive alcohol abuse, such as liver cirrhosis [13]. To our knowledge, no data exist on the mortality of alcoholic ICU patients beyond 30 days after ICU admission.

Data on the prognosis of alcoholic ICU patients are important for understanding their clinical course and thus for preventing complications in these high-risk patients. We conducted a cohort study encompassing more than 16,000 ICU patients to examine the association between alcoholism (with and without chronic complications of alcoholism) and mortality after intensive care.

\section{Materials and methods}

\section{Setting and study population}

The study cohort included ICU patients admitted between January 1, 2001, and December 31, 2007, to three ICUs (at Aalborg, Skejby, and Aarhus Hospitals) within the Aarhus University Hospital Collaboration, Aarhus, Denmark. Prospectively collected patient data were merged electronically into a research database known as the Aarhus University Intensive Care Cohort (AUICC) database. All ICUs in the Aarhus University Hospital Collaboration are highly specialized multidisciplinary tertiary teaching units serving as both primary and referral ICUs. Dedicated ICU teams are responsible for the care of all ICU patients. Together, the ICUs cover all major medical specialities. The nurse-to-patient ratio is $1: 1$.

We included only first-time ICU admissions during the study period and excluded patients transferred to the ICUs for planned postoperative observation of less than 24 hours. Also, only ICU patients older than 15 years were included. This yielded a study population of 16,848 first-time adult ICU patients. The AUICC database contains data on all ICU admissions during the study period, including date of ICU admission and discharge, use of mechanical ventilation, and renal replacement therapy.

\section{Identification of alcoholic patients}

We obtained data on all previous hospitalizations with complications of alcoholism (for example, alcoholic liver disease) through the Danish National Registry of Patients (DNRP) (for details, see Additional file 1). The DNRP contains key information on all inpatient hospitalizations at nonpsychiatric hospitals in Denmark since 1977 and on all outpatient clinic and emergency department visits since 1995 [16]. Data include patients' civil registration numbers, admission and discharge dates, department providing care, up to 20 surgical procedures, and up to 20 discharge diagnoses, coded according to the International Classification of Diseases, 8th edition (ICD-8) until the end of 1993, and 10th edition (ICD10) thereafter.

We obtained data on the use of alcohol deterrents (primarily disulfiram) and other prescription medications through a prescription database with complete coverage in the study region since 1998 [17]. The database contains key information on prescriptions for all reimbursed drugs dispensed from every pharmacy in the region. Danish guidelines specify disulfiram as the primary treatment for alcohol abuse.

Based on the complete hospital and prescription history of patients in the study cohort, we defined alcoholic patients as those with (a) at least one redeemed prescription for an alcohol deterrent within 1 year preceding ICU admission, and/or (b) at least one hospital or outpatient clinic/emergency department visit with a diagnosis of an alcoholism-related disease registered within 1 year of ICU admission (for details on ATC and ICD codes, see Additional file 1). Nonalcoholic ICU patients were defined as those without redeemed prescriptions for an alcohol deterrent and without any alcoholism-related diagnosis. The 1-year time window reduced the risk of incorrectly classifying former alcoholic patients as current alcoholics.

\section{Subcohorts of alcoholic ICU patients}

We further categorized alcoholic patients into two subcohorts: (a) patients with complications of alcoholism (that is, alcoholic psychosis, alcoholic pancreatitis, alcoholic liver diseases, alcoholic gastritis, alcoholic neuropathy, alcoholic myopathy, alcoholic dementia, and alcoholic cardiomyopathy); and (b) patients without complications of alcoholism (that is, those with alcohol dependence, alcohol abuse, and/or use of alcohol deterrents). Details on categorization based on diagnosis and prescription data are provided in the Additional file 1. We further identified the subgroup of patients in whom the alcoholic complication was liver cirrhosis.

In a sensitivity analysis, we categorized alcoholic patients based on their entire hospital and prescription history both since 1977 and since 1998.

\section{Covariates}

To control for the impact of comorbid diseases on mortality, we used the summary measure of comorbidities developed by Charlson et al. (the Charlson Comorbidity Index (CCI) score), by using a coding scheme validated for use with hospital discharge data [18-20]. The Charlson index includes 19 groups of major chronic diseases, including ischemic heart disease, cancer, diabetes, 
chronic lung diseases, and chronic renal failure. We obtained data on the complete post-1977 hospital history preceding the date of ICU admission from the DNRP to compute a CCI score for each patient. We defined three levels of comorbidity: low (score of 0 ); medium (score of 1 to 2); and high (score of $>2$ ). We did not include alcoholism-related diseases in the CCI, as they constituted our exposure variable.

We also used the DNRP to obtain data on the primary diagnoses associated with the hospitalization during which patients were admitted to the ICU, and on all surgical procedures performed on study patients within 30 days before ICU admission. To measure social status, we obtained data from the Danish Civil Registration System (CRS) on place of residence (that is, urban versus rural) and marital status at the time of ICU admission [21].

\section{Mortality data}

To obtain information on death or migration, we linked the study cohort to the Danish CRS, which has maintained a database on vital status (dead, alive) and exact date of death for the entire Danish population, updated daily, since 1968 [21,22].

\section{Statistical analysis}

Follow-up extended from the date of first-time ICU admission until death or migration or until 3 years after ICU admission, whichever came first. We computed Kaplan-Meier life-table estimates for 30-day and 3-year mortality for the main variables (that is, alcoholism with and without complications, age group (15 to 44,45 to 59, 61 to 74, and 75+ years), gender, level of comorbidity, primary hospital registry diagnosis (infectious disease, cancer, diabetes, cardiovascular disease, respiratory disease, gastrointestinal/liver disease, trauma/poisoning, and other), department providing care (medical/surgical), surgical procedures, type of admission (emergency/ planned), and marital status (married, divorced, never married, widow(er), unknown).

We used the Cox regression analysis to compare 30day and 3-year mortality among alcoholic patients with and without alcoholism-related complications with those of nonalcoholic patients. We estimated mortality rate ratios (MRRs) with 95\% confidence intervals (CIs), controlling for the covariates listed earlier and allowing a time-varying effect when relevant. Because age may influence the impact of alcoholism on mortality, we repeated the analysis stratified by age group. Some indications exist that alcoholism is associated with increased mortality after major surgery, and we therefore also did an analysis stratified by department (medical/surgical). Liver cirrhosis is associated with increased mortality after ICU admission, and we therefore also did a stratified analysis by liver cirrhosis among patients with alcoholic complications. Finally, we repeated the regression analysis after identifying and categorizing alcoholic patients on the basis of their entire available prescription and hospital history.

The assumptions of proportional hazards in the Cox model were assessed graphically and found appropriate for each follow-up period.

All analyses were performed by using SAS version 9.2 (SAS Institute Inc, Cary, NC)

All data were obtained from Danish registries, which are generally available to researchers, and their use does not require informed consent. The study was approved by the Danish Data Protection Agency and the Aarhus University Hospital Registry Board.

\section{Results}

We identified 16,848 first-time ICU patients, of whom $1,229(7.3 \%)$ were current alcoholics. Among these patients, 785 (4.7\%) had a prescription for an alcohol deterrent or a history of alcoholism-related hospitalization without complications of alcoholism within 1 year before ICU admission; 444 (2.6\%) had a history of alcoholism-related hospitalization with complications of alcoholism within 1 year before ICU admission (Table 1).

\section{Descriptive data}

Alcoholic patients were more likely to be men and were younger ( $26.4 \%$ were older than 60 years) than were nonalcoholic patients (55.7\% were older than 60 years). Alcoholic patients with complications of alcoholism had higher comorbidity scores than did other patients. For the hospitalization that required ICU admission, gastrointestinal diseases were more frequent among alcoholics than among nonalcoholics, whereas nonalcoholics were more often hospitalized with cardiovascular diseases and cancer (Table 2). Fifty-nine percent of alcoholic patients were transferred to the ICU from medical departments, compared with $40 \%$ of nonalcoholic patients. Slightly fewer alcoholic patients than nonalcoholic patients were treated with mechanical ventilation and renal replacement therapy. A total of 379 (51.7\%) alcoholic patients with complications were registered with a diagnosis of liver cirrhosis.

\section{0-day mortality}

Patients with alcoholism-related complications were at higher risk of death than were nonalcoholics throughout the follow-up period (Figure 1). Thirty-day mortality among alcoholic patients without complications was $15.9 \%$, increasing to $33.6 \%$ for alcoholic patients with complications, compared with $19.7 \%$ for nonalcoholic patients (Table 3). The corresponding adjusted 30-day 
Table 1 Baseline characteristics of alcoholic patients with and without complications and nonalcoholic patients admitted to ICUs within the Aarhus University Hospital Network, Denmark, 2001 to 2007

\begin{tabular}{|c|c|c|c|c|c|c|}
\hline & \multicolumn{2}{|c|}{ Nonalcoholic patients } & \multicolumn{2}{|c|}{ Alcoholic patients with complications } & \multicolumn{2}{|c|}{ Alcoholic patients without complications } \\
\hline & $(n)$ & (\%) & $(n)$ & $(\%)$ & $(n)$ & $(\%)$ \\
\hline Overall & 15,619 & 92.7 & 444 & 2.6 & 785 & 4.7 \\
\hline \multicolumn{7}{|l|}{ Age (years) } \\
\hline $15-44$ & 3,559 & 22.8 & 86 & 19.4 & 253 & 32.2 \\
\hline $45-59$ & 3,353 & 21.5 & 226 & 50.9 & 340 & 43.3 \\
\hline $60-74$ & 5,400 & 34.6 & 123 & 27.7 & 166 & 21.2 \\
\hline $75+$ & 3,307 & 21.2 & 9 & 2.0 & 26 & 3.3 \\
\hline \multicolumn{7}{|l|}{ Gender } \\
\hline Female & 6,530 & 41.8 & 130 & 29.3 & 239 & 30.5 \\
\hline Male & 9,089 & 58.2 & 314 & 70.7 & 546 & 69.6 \\
\hline \multicolumn{7}{|l|}{ Comorbidity score $^{a}$} \\
\hline Low & 6,481 & 41.5 & 124 & 27.9 & 395 & 50.3 \\
\hline Medium & 5,628 & 36.0 & 137 & 30.9 & 288 & 36.7 \\
\hline High & 3,510 & 22.5 & 183 & 41.2 & 102 & 13.0 \\
\hline \multicolumn{7}{|l|}{ Comorbidity } \\
\hline Ischemic heart disease & 1,682 & 10.8 & 17 & 3.8 & 18 & 2.3 \\
\hline Congestive heart failure & 1,564 & 10.0 & 27 & 6.1 & 30 & 3.8 \\
\hline Peripheral vascular disease & 1,550 & 9.9 & 27 & 6.1 & 38 & 4.8 \\
\hline Cerebrovascular disease & 1,915 & 12.3 & 46 & 10.4 & 82 & 10.5 \\
\hline COPD & 2,331 & 14.9 & 69 & 15.5 & 114 & 14.5 \\
\hline Diabetes & 1,389 & 8.9 & 67 & 15.1 & 56 & 7.1 \\
\hline Cancer & 2,831 & 18.1 & 41 & 9.2 & 73 & 9.3 \\
\hline \multicolumn{7}{|l|}{ Marital status } \\
\hline Married & 7,609 & 48.7 & 154 & 34.7 & 225 & 28.7 \\
\hline Divorced & 3,165 & 20.3 & 109 & 24.6 & 265 & 33.8 \\
\hline Widow(er) & 1,777 & 11.4 & 134 & 30.2 & 233 & 29.7 \\
\hline Never married & 2,402 & 15.4 & 29 & 6.5 & 45 & 5.7 \\
\hline Unknown & 666 & 4.3 & 18 & 4.1 & 17 & 2.2 \\
\hline
\end{tabular}

a Level of Charlson Comorbidity Index (see text for details). COPD, chronic obstructive pulmonary disease.

MRRs for alcoholic patients with and without complications were 1.64 (95\% CI, 1.38 to 1.95$)$ and 1.04 (95\% CI, 0.87 to 1.25$)$, respectively, compared with nonalcoholic patients.

\section{3-year mortality}

Among nonalcoholic patients, 3-year mortality was $40.9 \%$, compared with $36.2 \%$ among alcoholic patients without complications of alcoholism and 64.5\% among patients with complications. Adjusted MRRs for alcoholic patients with and without complications were 1.67 (95\% CI, 1.48 to 1.90 ) and 1.16 (95\% CI, 1.03 to 1.31 ), respectively, compared with nonalcoholic patients. The single most important confounding factor driving the relative risk from the unadjusted MRR of 0.84 to the adjusted MR of 1.16 was the age differences between alcoholic and nonalcoholic patients (as seen in Table 1).

For alcoholic patients younger than age 45 with complications of alcoholism, 30-day and 3-year MRRs were substantially increased (adjusted 30-day MRR, 3.26 (95\%
CI, 1.99 to 5.33), and adjusted 3-year MRR, 3.19 (95\% CI, 2.27 to 4.48)). The corresponding adjusted 30-day MRR for patients aged 75+ years was 1.07 (95\% CI, 0.44 to 2.58$)$, and the 3 -year adjusted MRR was 1.11 (95\% CI, 0.55 to 2.22 ). Among medical ICU patients, the adjusted 30-day MRR for those with complications of alcoholism was 1.57 (95\% CI, 1.25 to 1.97 ), and for those without complications, it was 0.78 (95\% CI, 0.60 to 1.02). For surgical ICU patients, the corresponding MRRs were 1.53 (95\% CI, 1.19 to 1.97 ) and 1.32 (95\% CI, 0.97 to 1.78 ), respectively. The increased 30 -day mortality among alcoholic patients with complications was restricted to those with liver cirrhosis (with liver cirrhosis, adjusted MRR was 1.92 (95\% CI, 1.59 to 2.33), and without liver cirrhosis, adjusted MRR was 0.98 (95\% CI, 0.66 to 1.45$)$ ). Among alcoholics with complications, 3 -year mortality for alcoholics with liver cirrhosis was $73.4 \%$, with $46.9 \%$ for alcoholics with noncirrhotic complications. When compared with those of nonalcoholics, adjusted MRRs were 1.89 (95\% CI, 1.64 to 2.18) for 
Table 2 Characteristics associated with the current hospitalization of ICU patients, Aarhus University Hospital Network, Denmark, 2001 to 2007

\begin{tabular}{|c|c|c|c|c|c|c|}
\hline & \multicolumn{2}{|c|}{$\begin{array}{l}\text { Nonalcoholic } \\
\text { patients }\end{array}$} & \multicolumn{2}{|c|}{$\begin{array}{l}\text { Alcoholic patients with } \\
\text { complications }\end{array}$} & \multicolumn{2}{|c|}{$\begin{array}{l}\text { Alcoholic patients without } \\
\text { complications }\end{array}$} \\
\hline & $n$ & $\%$ & $n$ & $\%$ & $n$ & $\%$ \\
\hline \multicolumn{7}{|c|}{ Planned/emergency hospital admission } \\
\hline Planned & 3,665 & 23.5 & 44 & 9.9 & 59 & 7.5 \\
\hline Emergency & 11,954 & 76.5 & 400 & 90.1 & 726 & 92.4 \\
\hline \multicolumn{7}{|l|}{ Primary diagnosis } \\
\hline Infectious disease & 392 & 2.5 & 15 & 3.4 & 33 & 4.2 \\
\hline Cancer & 2,208 & 14.1 & 15 & 3.4 & 42 & 5.4 \\
\hline Diabetes & 200 & 1.3 & 6 & 1.4 & 13 & 1.7 \\
\hline Cardiovascular disease & 4,310 & 27.6 & 93 & 21.0 & 84 & 10.7 \\
\hline Respiratory disease & 1,443 & 9.2 & 23 & 5.2 & 66 & 8.4 \\
\hline Gastrointestinal disease & 1,419 & 9.1 & 189 & 42.6 & 99 & 12.6 \\
\hline Trauma/poisoning & 3,255 & 20.8 & 44 & 9.9 & 275 & 35.0 \\
\hline Other & 2,393 & 15.3 & 59 & 13.3 & 173 & 22.0 \\
\hline \multicolumn{7}{|l|}{ Surgical procedures } \\
\hline No surgery & 7,830 & 50.1 & 339 & 76.4 & 555 & 70.7 \\
\hline Vascular & 2,647 & 17.0 & 15 & 3.4 & 37 & 4.7 \\
\hline Abdominal & 1,342 & 8.6 & 36 & 8.1 & 40 & 5.1 \\
\hline Orthopedic & 881 & 5.6 & 9 & 2.0 & 15 & 1.9 \\
\hline Thoracic & 743 & 4.8 & 29 & 6.5 & 48 & 6.1 \\
\hline $\begin{array}{l}\text { Central nervous } \\
\text { System }\end{array}$ & 1,452 & 9.3 & 8 & 1.8 & 54 & 6.9 \\
\hline Other & 724 & 4.6 & 8 & 1.8 & 36 & 4.6 \\
\hline \multicolumn{7}{|l|}{ Department } \\
\hline Surgical & 9,376 & 60.0 & 181 & 40.8 & 326 & 41.5 \\
\hline Medical & 6,243 & 40.0 & 263 & 59.2 & 459 & 58.5 \\
\hline \multicolumn{7}{|l|}{ Mechanical ventilation } \\
\hline Yes & 6,692 & 42.9 & 172 & 38.7 & 308 & 39.2 \\
\hline \multicolumn{7}{|c|}{ Renal replacement therapy } \\
\hline Yes & 1,160 & 7.4 & 38 & 8.6 & 46 & 5.9 \\
\hline
\end{tabular}

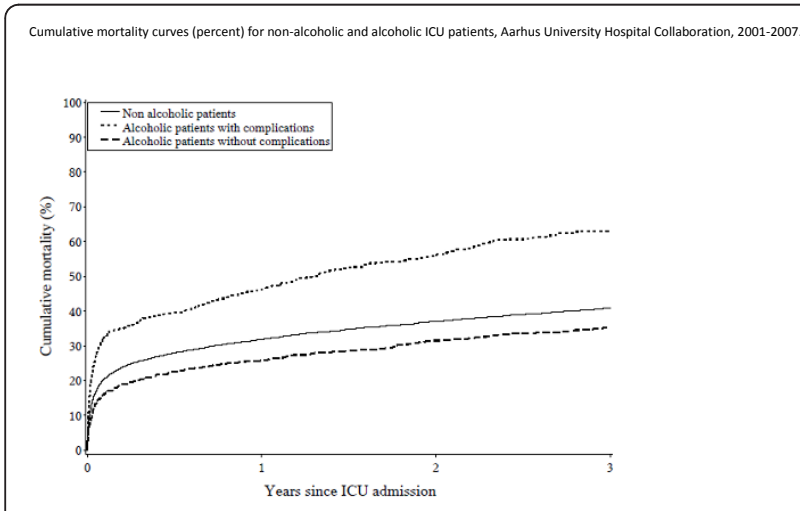

Figure 1 Cumulative mortality curves (percentages) for nonalcoholic and alcoholic ICU patients, Aarhus University Hospital Collaboration, 2001 to 2007. alcoholic patients with cirrhosis and 1.25 (95\% CI, 0.98 to 1.58 ) for alcoholics with noncirrhotic complications.

When identification and categorization were based on patients' entire prescription and hospital histories, MRRs for alcoholic patients with complications remained elevated, although at a slightly lower level (the 30-day adjusted MRR among alcoholics with complications was 1.44 (95\% CI, 1.24 to 1.67 ), and the 3 -year adjusted MRR was 1.55 (95\% CI, 1.39 to 1.71$)$ ).

\section{Discussion}

In this large cohort study, we found that alcoholic patients admitted to ICUs had substantially increased short- and long-term mortality if they had complications of alcoholism such as alcoholic liver disease. The increased mortality was most pronounced in alcoholics with liver cirrhosis. We found no increased 30-day 
Table 3 The 30-day and 3-year mortality and corresponding crude and adjusted mortality rate ratios for alcoholic and nonalcoholic ICU patients

\begin{tabular}{|c|c|c|c|c|c|c|}
\hline & 30-day mortality & & & 3-year mortality & & \\
\hline & Mortality \% (95\% Cl) & $\begin{array}{l}\text { Crude } \\
\text { MRR } \\
(95 \% \mathrm{Cl})\end{array}$ & $\begin{array}{l}\text { Adjusted MRR } \\
(95 \% \mathrm{Cl}) \Omega\end{array}$ & Mortality \% $(95 \% \mathrm{Cl})$ & $\begin{array}{l}\text { Crude MRR } \\
(95 \% \mathrm{Cl})\end{array}$ & $\begin{array}{l}\text { Adjusted MRR } \\
(95 \% \mathrm{Cl}) \Omega\end{array}$ \\
\hline \multicolumn{7}{|l|}{ Overall } \\
\hline Nonalcoholic patients & $19.7(19.1-20.3)$ & 1.0 (reference) & 1.0 (reference) & $40.9(40.1-41.6)$ & 1.0 (reference) & 1.0(reference) \\
\hline $\begin{array}{l}\text { Alcoholic patients, with } \\
\text { complications }\end{array}$ & $33.6(29.4-38.2)$ & $1.83(1.55-2.16)$ & $1.64(1.38-1.95)$ & $64.5(60.0-69.0)$ & $1.89(1.68-2.13)$ & $1.67(1.48-1.90)$ \\
\hline $\begin{array}{l}\text { Alcoholic patients, no } \\
\text { complications }\end{array}$ & $15.9(13.5-18.7)$ & $0.79(0.66-0.94)$ & $1.04(0.87-1.25)$ & $36.2(32.9-39.7)$ & $0.84(0.75-0.95)$ & $1.16(1.03-1.31)$ \\
\hline
\end{tabular}

$\Omega$ Adjusted by Cox proportional hazards analysis for age group, gender, department providing care (medical/surgical), primary diagnosis, surgery, Charlson index score, emergency/planned admission, and marital status.

mortality among alcoholics without complications and only slightly increased 3-year mortality.

Our data extend previous research findings on alcoholism and ICU outcomes in several ways, including complete long-term follow-up and better control for confounding, in particular, from comorbidity. A Danish cohort study published almost 20 years ago found significantly increased short-term mortality of $50 \%$ among alcohol abusers compared with $26 \%$ among nonabusers; however, the study did not control for potential confounders and did not report separate mortality estimates for those with and without complications of alcoholism [11].

In line with our findings, a 1996 German observational study reported increased short-term mortality (7\% versus 0) among chronic alcoholic patients admitted to a surgical ICU after major upper gastrointestinal surgery [8]. A 2007 U.S. observational study based on administrative data from "safety net" hospitals (primarily serving special populations, including the mentally ill and alcohol abusers) found that alcohol dependence among ICU patients in this setting was associated with significantly increased in-hospital mortality [13]. Also in accordance with our findings, alcohol dependence complicated by liver diseases was associated with higher in-hospital mortality rates than was alcohol dependence without such complications. This suggests that any increased mortality among alcoholic ICU patients may be caused, not by alcoholism itself but by the complications related to alcohol abuse. This is further supported by an Austrian cohort study reporting similar in-hospital mortality rates for alcoholics and nonalcoholic liver cirrhosis patients admitted to a mixed medical/surgical ICU [14]. In contrast, a Finnish cohort study reported similar inhospital mortality among patients admitted to ICUs with and without alcohol-related conditions; however, use of alcohol-related ICU admissions as the main exposure in contrast to chronic alcoholism used in the present study complicates further comparisons between the studies [15].
No previous study has presented separate mortality data for young and elderly alcoholic ICU patients. In the present study, the increased mortality appeared to be most pronounced among young alcoholic ICU patients. Why younger alcoholic patients have particularly high relative mortality in the years after ICU admission is not entirely clear. However, young alcoholics may be moresevere abusers, with an overall poorer prognosis than older alcoholics, when compared with nonalcoholic ICU patients in their age group. We lacked data to examine this further.

The longitudinal population-based medical databases used in our research permitted examination, for the first time, of long-term mortality among alcoholic ICU patients, with complete follow-up. Long-term mortality is more complex to interpret than 30-day mortality, when most deaths are directly linked to ICU admission. With increasing length of follow-up, patients may be more likely to suffer progression of their alcoholic complications and other lifestyle-related diseases, and to receive other treatments that may affect their prognosis. In particular, the modest increase in mortality among alcoholic patients with complications warrants careful interpretation. Still, from a public health perspective, data on long-term mortality among alcoholic ICU patients are important for understanding these patients' clinical course.

Accurate identification of alcoholic patients in ICUs is difficult and often prone to selection and information bias when based on interviews with the patients or their relatives. We identified alcoholic patients based on previous hospitalizations with alcohol-related disorders or by redemption of prescriptions for alcohol deterrents within 1 year before ICU admission [7]. This information was prospectively collected, independent of the current study, which largely eliminated the risk of selection and information biases. Co-payment requirements for alcohol deterrents most likely increase the specificity of information on their use. 
Misclassification of alcoholic patients because of underreporting of alcoholism-related diagnoses in the databases may have affected our results. In the current study, 7.3\% of all patients were classified as alcoholics. This is slightly lower than previously reported in a Danish ICU study (12\%) and substantially lower than reported from an inner-city hospital in the United Kingdom (28\%) [6,11]. These differences may be explained by differences in the definition of alcoholism and methods of identifying alcoholics in the ICUs (that is, register data versus interviews), but may also represent differences in case-mix among study cohorts. Such differences may explain at least part of the differences between studies on the prognosis of alcoholic ICU patients.

Use of previous hospitalizations and prescription drug use to identify alcoholic patients may have led to inclusion of only those alcoholic patients with the most severe alcohol abuse. This may have inflated our absolute mortality estimates. Any misclassification of alcoholic patients was most likely independent of mortality and therefore would lead to an underestimation of the relative mortality estimates. However, we found no increased mortality among alcoholics without complications of alcoholism, and identifying alcoholic patients based on their entire prescription history versus within 1 year before ICU admission had no major impact on relative mortality estimates. We therefore believe that any influence from such factors is most likely minor. Unfortunately, the registries used for the present study did not contain data on actual alcohol consumption. However, even in studies based on primary data collection, it is difficult to obtain valid data on actual alcohol consumption from ICU patients: alcoholic patients may not be entirely accurate about their actual alcohol consumption, or may be sedated or unconscious for other reasons.

Despite the free tax-supported Danish public health care system, it is possible that lack of ICU capacity leads to some reluctance to admit socially marginalized endstage alcoholic patients. This may have influenced our results. We may only speculate on the reason for the minor difference in mechanical ventilation between alcoholics and nonalcoholics. However, alcoholics are more likely than nonalcoholics to be admitted to the ICU because of nonrespiratory complications, such as upper GI bleeding, low Glasgow Coma Scale score, or severe electrolyte derangement. Thus differences in mechanical ventilation do not necessarily reflect differences in severity of illness. We lacked clinical data on severity of illness at ICU admission (for example, APACHE or SAPS scores). However, such scores were developed for clinical prediction rather than to control for confounding in etiologic research [23]. Also, chronic alcohol abuse induces immune dysfunction and failure of a number of organ systems included in severity-of-illness scores [24]. Thus the level of APACHE or SAPS scores may be considered an effect of alcoholism rather than a potential confounding factor [25]. Control for severity of illness potentially could bias the relative-risk estimates toward the null. In the present study, we controlled individually for a wide range of covariates, such as age and comorbidity. When used in a prediction model, these factors have been shown to predict ICU mortality as well as APACHE and SAPS scores [26]. We lacked data on lifestyle factors such as smoking and obesity, which may have influenced our results, but controlled for a wide range of consequences of these lifestyle factors, such as chronic lung diseases, ischemic heart diseases, cancer, diabetes, and chronic renal failure.

For several reasons, alcoholism may be associated with increased mortality after ICU admission [10]. Physiological changes associated with alcoholism include immune suppression $[27,28]$, acute renal failure, alteration of hemostatic functions [29] and stress responses [30], poor wound healing [31], and congestive heart failure $[32,33]$. Critically ill alcoholic patients often have complications requiring urgent and specific treatments, such as alcoholic ketoacidosis, lactate acidosis, severe electrolyte disturbances, or delirium from alcohol withdrawal [24].

In clinical settings, early recognition and treatment of these alcoholism-specific conditions is complicated by difficulty identifying alcoholic patients. Subsequent delayed treatment may increase mortality [34]. The current study indicates that special attention should be paid to ICU patients with chronic complications of alcoholism.

\section{Conclusion}

Alcoholic patients with chronic complications of alcoholism have substantially increased short-term and longterm mortality after ICU admission. Thirty-day mortality was not increased among alcoholics without complications, and 3-year mortality was only slightly increased.

\section{Key messages}

- Alcoholism and alcoholism-related complications are common in intensive care unit patients

- Alcoholic patients with chronic complications of alcohol abuse have substantial increased 30-day and 3-year mortality

- In alcoholic patients without alcoholism-related complications, 30-day mortality is not increased, and 3 -year mortality is only slightly increased 


\section{Additional material}

Additional file 1: A. International Classification of Diseases (ICD)-10 Codes and Anatomical Therapeutic Chemical (ATC) prescription codes used for identification and classification of alcoholic patients. International Classification of Diseases (ICD)-10 codes and Anatomical Therapeutic Chemical (ATC) prescription codes used for identification and classification of alcoholic patients with and without alcohol-related complications and liver cirrhosis. B. Charlson Comorbidity Index and comorbidity groups. ICD-8 and ICD-10 codes used to identify diagnosis included in the Charlson Comorbidity Index and a description of the groups of chronic diseases.

\section{Abbreviations}

AUICC: Aarhus University Intensive Care Cohort; CCl: Charlson Comorbidity Index; Cl: confidence interval; CRS: Civil Registration System; DNRP: Danish National Registry of Patients; ICD: International Classification of Diseases; ICU: intensive care unit; MRR: mortality rate ratio.

\section{Acknowledgements}

This research was made possible through financial support from the Danish Medical Research Council (grant 271-05-0511) and from the Klinisk Epidemiologisk Forskningsfond, Denmark.

\section{Author details}

'Department of Clinical Epidemiology, Aarhus University Hospital, Olof Palmes alle 43-45, Aarhus N, 8240, Denmark. Department of Anaesthesiology and Intensive Care, Aarhus University Hospital, Skejby Hospital, Brendstrupgårdsvej 100, Aarhus N, 8240, Denmark. ${ }^{3}$ Department of Anaesthesiology and Intensive Care, Aarhus Hospital, Aarhus University Hospital, Nørrebrogade 44, Aarhus C, 8000, Denmark. ${ }^{4}$ Department of Anaesthesiology and Intensive Care Medicine, Uppsala University, Uppsala S751 85, Sweden. ${ }^{5}$ Department of Medicine V (Hepatology and Gastroenterology), Aarhus University Hospital, Aarhus Hospital, Aarhus Hospital, Nørrebrogade 44, Aarhus C, 8000, Denmark.

\section{Authors' contributions}

SC, AL, ET, RJ, KML, and HTS conceived the study idea. SC, MBJ, CFC, and HTS designed the study. LAP, HTS, RJ, and KML collected the data. MBJ, SC, CFC, and LP analyzed the data. All authors interpreted the findings. SC, CFC, and $\mathrm{AL}$ reviewed the literature. SC wrote the first draft, and all authors edited the manuscript and approved the final version.

\section{Competing interests}

The authors declare that they have no competing interests.

Received: 26 September 2011 Revised: 3 November 2011 Accepted: 8 January 2012 Published: 8 January 2012

\section{References}

1. O'Connor PG, Schottenfeld RS: Patients with alcohol problems. N Engl J Med 1998, 338:592-602.

2. Gacouin A, Legay F, Camus C, Volatron AC, Barbarot N, Donnio PY, Thomas R, Le TY: At-risk drinkers are at higher risk to acquire a bacterial infection during an intensive care unit stay than abstinent or moderate drinkers. Crit Care Med 2008, 36:1735-41.

3. Gado-Rodriguez M, Gomez-Ortega A, Mariscal-Ortiz M, Palma-Perez S, Sillero-Arenas M: Alcohol drinking as a predictor of intensive care and hospital mortality in general surgery: a prospective study. Addiction 2003, 98:611-6.

4. Marik P, Mohedin B: Alcohol-related admissions to an inner city hospital intensive care unit. Alcohol Alcohol 1996, 31:393-6.

5. Maxson PM, Schultz KL, Berge KH, Lange CM, Schroeder DR, Rummans TA: Probable alcohol abuse or dependence: a risk factor for intensive-care readmission in patients undergoing elective vascular and thoracic surgical procedures; Mayo Perioperative Outcomes Group. Mayo Clin Proc 1999, 74:448-53.
6. Mostafa SM, Murthy BV: Alcohol-associated admissions to an adult intensive care unit: an audit. Eur J Anaesthesiol 2002, 19:193-6.

7. Saitz R, Ghali WA, Moskowitz MA: The impact of alcohol-related diagnoses on pneumonia outcomes. Arch Intern Med 1997, 157:1446-52.

8. Spies CD, Nordmann A, Brummer G, Marks C, Conrad C, Berger G, Runkel N, Neumann T, Müller C, Rommelspacher H, Specht M, Hannemann L, Striebel HW, Schaffartzik W: Intensive care unit stay is prolonged in chronic alcoholic men following tumor resection of the upper digestive tract. Acta Anaesthesiol Scand 1996, 40:649-56.

9. Spies $C D$, Neuner B, Neumann T, Blum S, Müller C, Rommelspacher H, Rieger A, Sanft C, Specht M, Hannemann L, Striebel HW, Schaffartzik W: Intercurrent complications in chronic alcoholic men admitted to the intensive care unit following trauma. Intensive Care Med 1996, 22:286-93.

10. Tonnesen $\mathrm{H}$, Kehlet $\mathrm{H}$ : Preoperative alcoholism and postoperative morbidity. Br J Surg 1999, 86:869-74.

11. Jensen NH, Dragsted L, Christensen JK, Jorgensen JC, Qvist J: Severity of illness and outcome of treatment in alcoholic patients in the intensive care unit. Intensive Care Med 1988, 15:19-22.

12. Sørensen HT, Lash TL, Rothman KJ: Beyond randomized controlled trials: a critical comparison of trials with nonrandomized studies. Hepatology 2006, 44:1075-82.

13. O'Brien JM Jr, Lu B, Ali NA, Martin GS, Aberegg SK, Marsh CB, Lemeshow S, Douglas IS: Alcohol dependence is independently associated with sepsis, septic shock, and hospital mortality among adult intensive care unit patients. Crit Care Med 2007, 35:345-50.

14. Zauner C, Schneeweiss B, Kranz A, Klos H, Gendo A, Ratheiser K, Lenz K, Kramer L, Madl C: Heavy chronic alcohol abuse has no additional adverse effect on the function of extrahepatic organs and ICU mortality in patients with liver cirrhosis. Wien Klin Wochenschr 1999, 111:810-4.

15. Uusaro A, Parviainen I, Tenhunen JJ, Ruokonen E: The proportion of intensive care unit admissions related to alcohol use: a prospective cohort study. Acta Anaesthesiol Scand 2005, 49:1236-40.

16. Ehrenstein V, Antonsen S, Pedersen L: Existing data sources for clinical epidemiology: Aarhus University Prescription Database. Clin Epidemiol 2010, 2:273-9.

17. Andersen TF, Madsen M, Jorgensen J, Mellemkjoer L, Olsen JH: The Danish National Hospital Register: a valuable source of data for modern health sciences. Dan Med Bull 1999, 46:263-8.

18. Charlson ME, Pompei $P$, Ales KL, Mackenzie CR: A new method of classifying prognostic comorbidity in longitudinal studies: development and validation. J Chronic Dis 1987, 40:373-83.

19. Thygesen SK, Christiansen CF, Christensen S, Lash TL, Sørensen HT: The predictive value of ICD-10 diagnostic coding used to assess Charlson comorbidity index conditions in the population-based Danish National Registry of Patients. BMC Med Res Methodol 2011, 11:83.

20. Deyo RA, Cherkin DC, Ciol MA: Adapting a clinical comorbidity index for use with ICD-9-CM administrative databases. J Clin Epidemiol 1992, 45:613-9.

21. Pedersen CB, Gøtzsche H, Møller JO, Mortensen PB: The Danish Civil Registration System: a cohort of eight million persons. Dan Med Bull 2006, 3:441-9.

22. Frank L: Epidemiology: when an entire country is a cohort. Science 2000, 287:2398-9.

23. Le Gall Jr, Lemeshow S, Saulnier F: A new Simplified Acute Physiology Score (SAPS II) based on a European/North American multicenter study. JAMA 1993, 270:2957-63.

24. Moss M, Burnham EL: Alcohol abuse in the critically ill patient. Lancet 2007, 368:2231-42.

25. Rothman KJ: Epidemiology, an introduction. 1 edition. New York: Oxford University Press; 2002.

26. Christensen $\mathrm{S}$, Johansen MB, Christiansen CF, Jensen R, Lemeshow S: Comparison of Charlson comorbidity index with SAPS and APACHE scores for prediction of mortality following intensive care. Clin Epidemiol 2011, 3:203-11.

27. Chiappelli F, Kung M, Lee P, Pham L, Manfrini E, Villanueva P: Alcohol modulation of human normal T-cell activation, maturation, and migration. Alcohol Clin Exp Res 1995, 19:539-44.

28. Jerrells TR: Immunodeficiency associated with ethanol abuse. Adv Exp Med Biol 1991, 288:229-36.

29. Rubin R: Effect of ethanol on platelet function. Alcohol Clin Exp Res 1999, 23:1114-8 
30. Groote VR, Meinders AE: On the mechanism of alcohol-induced pseudoCushing's syndrome. Endocr Rev 1996, 17:262-8.

31. Rantala A, Lehtonen OP, Niinikoski J: Alcohol abuse: a risk factor for surgical wound infections? Am J Infect Control 1997, 25:381-6.

32. Patel VB, Why HJ, Richardson PJ, Preedy VR: The effects of alcohol on the heart. Adverse Drug React Toxicol Rev 1997, 16:15-43.

33. Thomas AP, Rozanski DJ, Renard DC, Rubin E: Effects of ethanol on the contractile function of the heart: a review. Alcohol Clin Exp Res 1994, 18:121-31

34. Spies C, Tonnesen H, Andreasson S, Helander A, Conigrave K: Perioperative morbidity and mortality in chronic alcoholic patients. Alcohol Clin Exp Res 2001, 25:164S-70S.

doi:10.1186/cc10603

Cite this article as: Christensen et al:: Three-year mortality among alcoholic patients after intensive care: a population-based cohort study. Critical Care 2012 16:R5

\section{Submit your next manuscript to BioMed Central} and take full advantage of:

- Convenient online submission

- Thorough peer review

- No space constraints or color figure charges

- Immediate publication on acceptance

- Inclusion in PubMed, CAS, Scopus and Google Scholar

- Research which is freely available for redistribution

Submit your manuscript at www.biomedcentral.com/submit 